\title{
A Simplified Zonal Model for The Evaluation of the Spatial Distribution of Air Temperature in Indoor Environments
}

\author{
Jean Pierre Campana ${ }^{1}$, Matthias Schuss ${ }^{2}$, Ardeshir Mahdavi ${ }^{2}$, Gian Luca Morini ${ }^{1}$ \\ ${ }^{1}$ Department of Industrial Engineering (DIN) - Alma Mater Studiorum, Bologna, Italy \\ ${ }^{2}$ Department of Building Physics and Building Ecology -Technical University, Wien, Austria
}

\begin{abstract}
Usually, in dynamic building energy simulation software the spatial distribution of air temperature within a zone, useful for the analysis of local comfort conditions, is not available. Co-simulation with CFD codes can overcome this problem but computational costs increase exponentially. In this paper, a new simplified zonal model, able to model in a simple way the air convective flows due to buoyancy forces, is proposed and implemented in the dynamic simulation software ALMABuild. The reduced CPU time required by the model to simulate the mass and energy exchanges among nodes allows an accurate analysis of multi-zone buildings avoiding heavy co-simulations.
\end{abstract}

\section{Introduction}

After the adoption of the Energy Performance of Buildings Directive (EU, 2010), designers are asked to develop buildings which are able to guarantee high comfort conditions but, at the same time, with lower consumptions of primary energy. This ambitious challenge can be achieved only if the designers are assisted by numerical tools able to fully simulate complex energy systems optimized for the reduction of the energy demand and the exploitation of renewable energies. Building Energy Simulation (BES) software represent the best tools for studying the dynamic behaviour of each building and HVAC component. In the most diffuse BES software (i.e. TRNSYS (Klein et al., 2010) and EnergyPlus (Crawley et al., 2000)) each thermal zone is characterized by a single value of the indoor air temperature because, typically, a one-node model is adopted for the evaluation of the convective heat transfer. This unique value of the air temperature coupled to a thermal zone represents the uniform value of air temperature obtained in presence of a perfect air mix; in this way, the spatial distribution of the air temperature within the zone is lost. As a consequence, it becomes impossible to use this software in order to obtain detailed information about the local indoor comfort conditions in a room.

In order to overcome this problem, Computational Fluid Dynamics (CFD) analysis can be coupled to BES software. CFD methods enable to obtain the distribution of the air temperature (and velocity) in the zone by solving the continuum, momentum and energy balance equations in a number of cells (sub-volumes) in which the zone is subdivided. CFD results give important information about the air flow distribution in a room (i.e. local velocity, turbulence level, temperature and so on). By means of these detailed data one can reconstruct the local comfort conditions in each sub-volume. However, accurate CFD simulations can be time consuming and, in general, can require high computational costs which become incompatible with complete seasonal dynamic simulations of complex buildings and plants.

For this reason, in the last time zonal models have been proposed for the local solution of the mass, momentum and energy balance equations in a zone. By means of these models, the zone is divided in a limited number of air cells (Wurtz et al., 1999). For each air cell, the governing balance equations, written in a simplified way, are solved with a reduced computational effort by enabling the local calculation of the main air parameters. In literature many zonal models can be found. As an example, Inard et al. (1996) used a zonal model with the aim to show the impact of 6 different heater configurations on the temperature field in a room. Nowadays, zonal models are implemented in various software, like SIM_ZONAL (Wurtz et al., 2003) a tool used for the evaluation of the thermal comfort and air flow distribution in buildings. As an example, Wurtz et al. (2006) used this software for the estimation of the impact on comfort conditions of an electric heater and a fan-coil. Again, Megri and Yu (2015) proposed a zonal model based on an upgraded pressurized model (POMA+) by means of which the effect of three different heater configurations (active surfaces) on the air flow pattern in a room was analysed.

It has to be remarked that in all these works, only the effect of the emitter configuration on the thermal conditions of the room was analysed; the focus was put on the building model and the HVAC system was not taken into account (or modelled in a very simple way). Up to day, BES software able to carry out annual evaluations of the local temperature distribution in a thermal zone and, at the same time, to simulate the dynamic behaviour of a complete HVAC system is rare. In many cases, this can be done only by adopting co-simulation (i.e. coupling different software (Daoud et al., 2008)).

For these reasons, in this paper a "simplified" zonal model is described and implemented in a SIMULINK library called ALMABuild (Campana et al., 2017). ALMABuild is a SIMULINK open toolbox which contains the dynamic model of each building element. This library can 
be easily coupled to ALMAHVAC (Magni et al.,2017), CARNOT (Wemhöner et al., 2000) and other SIMULINK open toolbox used for the simulation of HVAC systems with the aim to obtain a complete model of a buildingHVAC system.

In this way, a complete analysis of the mutual interactions among emitters, envelope elements and HVAC control system devices can be performed, enabling the evaluation of local comfort conditions and of energy demand for space heating with the adoption of a single software.

In this paper, the adopted zonal model will be used in order to evaluate the impact on the air temperature distribution of the position of the temperature sensor in an office. It is demonstrated that the position of the temperature sensor which control the heat emission in the office can influence both indoor thermal comfort conditions and yearly energy consumptions.

\section{Method}

\section{Zonal models}

Zonal models are based on a coarse spatial discretization of a thermal zone based on a limited number of subvolumes (or air cells). The air temperature of each air cell is assumed to be perfectly mixed and it is evaluated by solving a simplified energy balance in which the heat transfer with adjacent cells or building elements through the appropriate contact area is accounted for.

Each cell can exchange with the adjacent cells mass and heat by means of convection. The mass conservation applies both considering the total air mass or the diffusion of the single components (like VOC, humidity, $\mathrm{CO}$ and so on). By solving a set of coupled balance equations, the air temperature distribution in a room and the air flow can be estimated. The most critical point of a zonal model consists in the evaluation of the air mass flow rate between the cells. A widely used approach (adopted, among others, by Daoud et al. (2008), Haghighat et al. (2001), Boukhris et al. (2009) and Wurtz et al. (1999)) for the estimation of the air flow rate between adjacent cells, $\dot{m}$, is the adoption of the power law equations, whose general formulation is:

$$
\dot{m}=C_{d} A \rho \Delta P^{n}
$$

where $A$ represents the contact area of two adjacent cells $\left(\mathrm{m}^{2}\right), \rho$ is the air density $\left(\mathrm{kg} / \mathrm{m}^{3}\right), \Delta P$ is the pressure difference between the two cells $(\mathrm{Pa}), n$ is the flow exponent that depends on the air flow regime, and $C d$ is the discharge coefficient, that Wurtz et al. (1999) suggest to be a constant equal to $0.83 \mathrm{~m} \mathrm{~s}^{-1} \mathrm{~Pa}^{-\mathrm{n}}$. However, in more recent research, Teshome and Haghighat (2006) propose the use of variable discharge coefficient, obtained by means of detailed measurements or CFD analysis.

This pressure-based zonal model is not valid in presence of driving flows due to jets or plume, since a net non-zero air velocity in a cell is not considered. Inard et al. (1996) for solving this problem propose the use of pressure-based zonal model for the so called "current zones", whilst for the "driving zones", i.e. air cells characterised by the presence of driving flows, specific flow laws are suggested. In particular, correlations for the evaluation of the air flow due to jet, plume and thermal boundary layer are proposed. Musy et al. (2002) improved this method, defining a threshold for the air velocity: under the threshold in a driving zone the same equations of a current zone are adopted. Nevertheless, both the methods have important limitations, since the most suitable correlation has to be selected, for each cell, before performing a simulation, requiring an "a priori" knowledge of the air flow pattern in the zone. Moreover, correlations cannot be changed during the simulations, which represents a drawback when simulating intermittent operations of heating systems. In fact, a correlation that is adequate for the plume of a heater when this is switched on may not be suitable when the heater is off.

Even if the computational effort of a zonal model is much lower of that of a CFD simulation, up to day, there is a lack of a software that is able to evaluate the temperature distribution of a thermal zone and to simulate the behaviour of a HVAC system; these kind of analysis can be done only by using co-simulation by coupling different models implemented in different software, as described by Daoud et al. (2008).

For these reasons, with the aim to couple directly BES with zonal models, in ALMABuild a simplified zonal model has been directly implemented.

\section{Description of the simplified zonal model}

The zonal model adopted in this study and implemented in the ALMABuild library is based on a series of air cells (sub-volumes) in which air temperature is obtained by solving a simplified energy balance.

In order to evaluate the heat transfer among adjacent cells, heat transfer coefficients are associated to each contact area (layer). These heat transfer coefficients are calculated starting from a rough estimation of the mass flow among the cells. For each layer $k$ the following energy balance is written:

$$
q_{k}=m_{k} c p\left(\vartheta_{i}-\vartheta_{j}\right)=h_{k} A_{k}\left(\vartheta_{i}-\vartheta_{j}\right)
$$

where $q_{k}$ is the thermal power (W) exchanged between cell $i$ and cell $j$ (divided by the layer $k$ ), $m_{k}$ is the air flow $(\mathrm{kg} / \mathrm{s})$ through the layer $k, c p$ is the specific heat of air $(\mathrm{J} / \mathrm{kg} \mathrm{K}), \vartheta$ is the cell temperature $\left({ }^{\circ} \mathrm{C}\right), h$ is the heat transfer coefficient $\left(\mathrm{W} / \mathrm{m}^{2} \mathrm{~K}\right)$ linked to the layer $k$ and $A_{k}$ is the contact area between the two cells $\left(\mathrm{m}^{2}\right)$. From equation (2) the heat transfer coefficient can be linked in a simplified way to the air mass flow rate across the layer $k$ as follows:

$$
h_{k}=\frac{m_{k} c p}{A_{k}}
$$

By knowing $c p$ and the contact area $A_{k}$, the heat transfer coefficient is known if the air mass flow rate between the cells is defined. A simplified momentum balance is written for each layer in order to obtain the air mass flow rate under the hypothesis that air flow is assumed to be driven only by buoyancy forces (no forced convection) and considering the atmospheric pressure as reference 
pressure. The expression of the momentum balance varies for horizontal or vertical layers (see Figure 1).

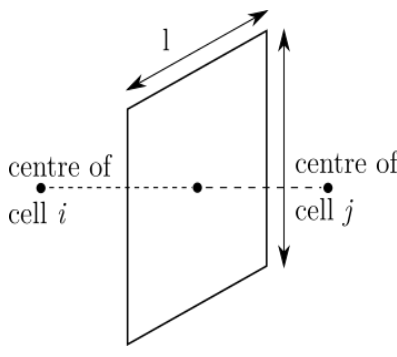

(a)

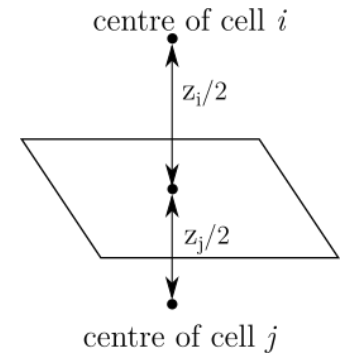

(b)
Figure 1: Vertical (a) and horizontal (b) layers between cells

The air mass flow rate across a vertical layer (see Figure 1a) is estimated evaluating the position of the neutral point, which is the point where there is no pressure difference between the adjacent cells. Since only buoyancy forces are here considered, the neutral point is located at the middle height of the layer. In this way, following (Wurtz et al., 1999), the air mass flow rate across a vertical layer $k$ can be estimated as follows:

$$
m_{k}=\frac{\left(\rho_{i}+\rho_{j}\right) C_{d} l|\Delta \rho g|^{n}(z / 2)^{n+1}}{n+1}
$$

In equation (4) $C_{d}$ is the discharge factor, set to $0.83 \mathrm{~m} \mathrm{~s}^{-}$ ${ }^{1} \mathrm{~Pa}^{-\mathrm{n}}$ as suggested in (Wurtz et al., 1999), $l$ is the width of the layer $(\mathrm{m}), z$ is the height of the layer $(\mathrm{m}), g$ is the gravitational acceleration $\left(\mathrm{m} / \mathrm{s}^{2}\right)$ and $n$ is the flow exponent, equals to 0.5 or 1 for laminar or turbulent flow regime respectively (Wurtz et al., 1999).

For horizontal layers (Figure 1b) the pressure power law is used for estimating the air flow and the pressure difference between the adjacent cells is calculated by using the Bernoulli's equation:

$$
m_{k}=C_{d} \rho_{i j} A_{k}\left|\frac{\rho_{i} z_{i}-\rho_{j} z_{j}}{2} g\right|^{n}
$$

where $\rho_{i j}$ is the mean air density $\left(\mathrm{kg} / \mathrm{m}^{3}\right)$ in cells $i$ and $j$. The air density in each cell is evaluated according to the perfect gas law; since the reference pressure is assumed to be constant for each cell, the air density depends only on the temperature of the cell.

The air flow regime (i.e. laminar or turbulent) is estimated evaluating the local value assumed by the Rayleigh number $(R a)$. If the Rayleigh number is lower than $10^{9}$, the flow is considered laminar, otherwise is turbulent, in agreement with (Rajput, 1999).

The heat transfer between air cells and building elements (e.g. walls, windows, floors, ceilings...) is evaluated by means of the convective heat transfer coefficients reported in the European Standard EN ISO 6946 (CEN, 2007). The overall convective heat transfer coefficients between the air cells and a building element is estimated considering the surface temperature of the building element and the mean air temperature $\left(T_{a v, a i r}\right)$ obtained as average value of the air temperature values coupled to all the cells of the zone.

\section{Case Study}

An application of the zonal model described in the previous Section, coupled to the detailed radiative model implemented in ALMABuild and described in (Magni et al, 2019), is shown by means of a case study. The goal of this study is to investigate the effect of the room temperature sensor position on the local indoor comfort conditions and on the energy consumptions of the heating system.

A multi-zone building located in Bologna (Italy), composed by three identical adjacent offices of $25 \mathrm{~m}^{2}$ (5 x $5 \mathrm{~m}$ ), is considered. Each office is $2.7 \mathrm{~m}$ height and has a double pane window of $1.35 \mathrm{~m}^{2}$ in the South wall, as shown in Figure 2.

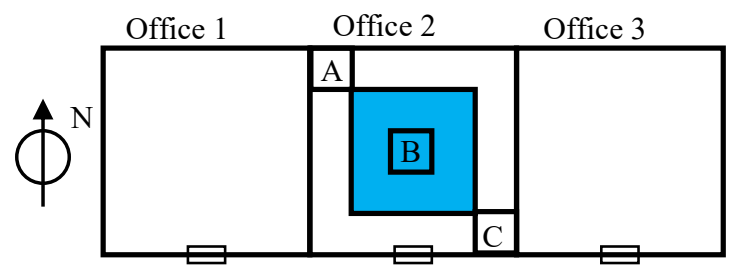

Figure 2 - Plant view of the offices. Comfort zone is evidenced in blue, whilst A, B and C refer to the position of the temperature sensor.

The roof is horizontal with a thermal insulation layer (thermal conductivity equal to $0.039 \mathrm{~W} /(\mathrm{m} \mathrm{K})$ ) of $6 \mathrm{~cm}$. External walls have an insulation layer of $8 \mathrm{~cm}$. No insulation is provided for the internal walls which separate the offices; on the contrary, the slab-on-grade floor contains $6 \mathrm{~cm}$ of insulation. The U-values of the office envelope elements are listed in Table 1.

Table 1: Thermal transmittance (U-value) of building elements $\left[W /\left(m^{2} K\right)\right]$

\begin{tabular}{|c|c|}
\hline Elements & U-value \\
\hline External wall & 0.31 \\
\hline Internal wall & 0.99 \\
\hline Floor & 0.27 \\
\hline Roof & 0.42 \\
\hline Window & 1.1 \\
\hline
\end{tabular}

The analysis of energy consumptions and comfort conditions is restricted to Office 2. In Figure 2, the blue central zone of Office 2 represents the area in which comfort conditions have to be optimized. A, B and C represent three different positions in which the temperature sensor will be placed. The coarse discretization of room, adopted for the definition of the air cells used in the model, is shown in Figure 3. Air cells of $1 \mathrm{x} 1 \mathrm{~m}$ in $\mathrm{x}-\mathrm{y}$ plane (Fig. 3a), and with different heights (Fig.3b) are adopted.

The room temperature sensor is $1 \mathrm{~m}$ from the floor and it is contained in the central air cell corresponding to position $\mathrm{A}, \mathrm{B}, \mathrm{C}$. Position $\mathrm{A}$ and $\mathrm{C}$ are typical positions used for indoor sensors (i.e. close to the emitter $(C)$ or close to the opposite wall with respect the emitter (A)), whereas position B represents the position of an "ideal" sensor placed in the middle of the comfort zone. 


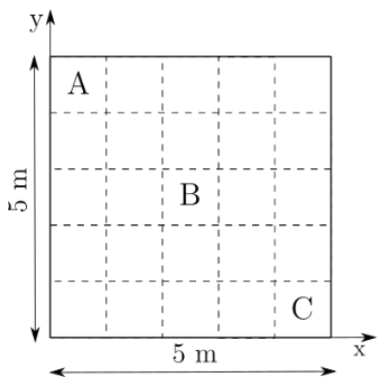

(a)

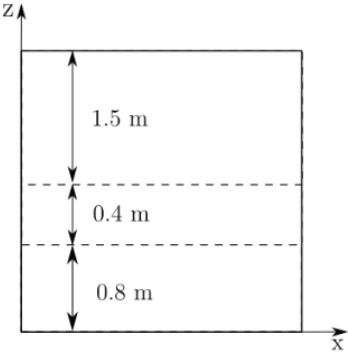

(b)
Figure 3 - Room discretization in air cells, plant view (a) and height discretization (b).

Each room is heated by means of a radiator, located under the window, which releases a thermal power equal to:

$$
\dot{Q}_{\text {rad }}=n_{e l} q_{\text {nom }}\left(\frac{T_{m r}-T_{a v, a i r}}{50}\right)^{r}
$$

where $q_{\text {nom }}$ is the nominal power per element (103 W/element), $r$ is the exponent equal to 1.32 and $T_{m r}$ is the mean temperature of the surface of the radiator. The water content is 1.44 1/element. The emitters are sized imposing a temperature difference of $10 \mathrm{~K}$ between inlet and outlet. The nominal inlet water temperature is set to $80{ }^{\circ} \mathrm{C}$. According to these settings, the radiator is composed by 12 elements.

The heating is activated from 6:00 to 20:00 each day; during the night the heating system is off. The heating system is switched on one hour before people starts to work. For sake of simplicity, in this model when heating is switched on, radiator receives a constant inlet water flow, set to the nominal value. In any case, a winter set point of $20^{\circ} \mathrm{C}$ (indoor comfort temperature), with a dead band of $1 \mathrm{~K}$, is used in order to control the heat emission of the radiators. Two different control strategies are analysed: (i) weather compensation is adopted in order to vary the inlet water temperature to the radiator as a function of the external temperature; (ii) no weather compensation control but the inlet water temperature is considered as independent by the outdoor temperature $\left(80^{\circ} \mathrm{C}\right)$.

\section{Results}

Numerical simulations have been performed by using ALMABuild for the whole heating season starting from October 15 to April 15 by considering the TRY data of Bologna.

The indoor thermal comfort conditions in Office 2 (see Figure 2) during the winter season are analysed by means of the estimation of:

(i) the comfort time $\left(\tau_{c}\right)$, i.e. the percentage of the winter working time in which the operative temperature in the blue region of Figure 2 is between 19.5 and $20.5^{\circ} \mathrm{C}$;

(ii) the overheating time $\left(\tau_{o h}\right)$, i.e. the percentage of the working time during which overheating conditions (operative temperature greater than $20.5{ }^{\circ} \mathrm{C}$ ) are observed in the blue region of Figure 2.
The effects on the heating system behaviour are analysed by recording during simulations the following parameters:

(i) the mean heating time $\left(t_{o n}\right)$, i.e. the average heating time between two consecutive shutdown of the radiator;

(ii) the mean shutdown time $\left(t_{\text {off }}\right)$, i.e. the average shutdown time between two consecutives on-cycles;

(iii) the seasonal operating time $\left(t_{o n, y}\right)$, i.e. the total amount of hours in which the radiator is on during the winter;

(iv) the total energy demand $(E)$, i.e. the energy released by radiators to the room.

\section{Cases without weather compensation control}

In Figure 4, the cumulative distribution of the mean operative temperature in Office 2 during the whole winter by considering only the working time (7:00-20:00 each day) is shown. From this Figure different cumulative distributions are observed for various temperature sensor positions. Dashed black lines are used in Figure 5 to represent the target band of the operative temperature $\left(19.5-20.5^{\circ} \mathrm{C}\right)$.

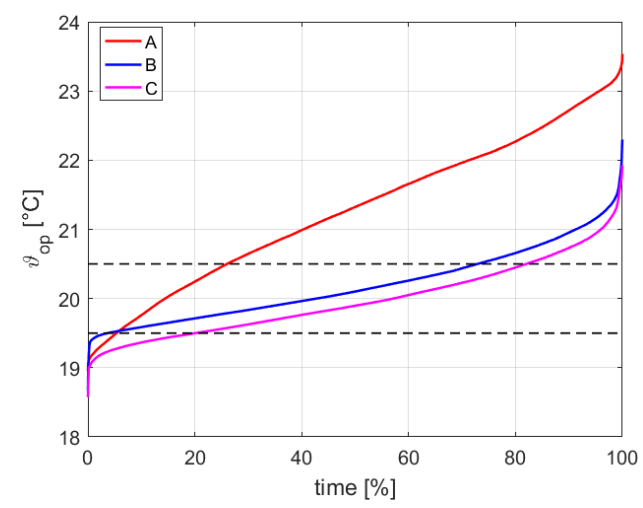

Figure 4: Cumulative distribution of the mean operative temperature of the comfort zone, for cases with constant water inlet temperature.

The cumulative distribution of the operative temperature $\left(\vartheta_{\mathrm{op}}\right)$, when the sensor is located in A (red line) close to the North external wall and far from the radiator, is contained for a short period within the target band. The prevalent portion of the red line lies above the upper threshold value of the target band, revealing the presence of frequent overheating conditions.

On the contrary, if the sensor is moved in B (blue line), i.e. in the middle of the comfort zone, the cumulative distribution of the operative temperature is contained in the target band for a bigger fraction of the winter working time. However, overheating conditions still appear with a significant frequency, around the $30 \%$ of the winter working time.

Moving the sensor near to the South external wall close to the radiator (position $\mathrm{C}$, magenta line), a portion of the cumulative distribution, similar to that observed for case $\mathrm{B}$, is still contained into the target band, but in this case undercooling conditions (i.e. operative temperature lower than $19.5^{\circ} \mathrm{C}$ ) appear. Therefore, overheating conditions are less frequent. It should be noted that the shape of the 
trend of the cumulative distribution of the operative temperature in case $\mathrm{C}$ and $\mathrm{B}$ is very similar.

The observations deduced from Figure 4 are confirmed by the results collected in Table 2. In fact, it can be observed that the yearly comfort time is around $20 \%$ if the sensor is placed on the external wall (A), otherwise the comfort time becomes higher than $60 \%$. Moreover, when the sensor is located close to the emitter (position C) undercooling conditions appears (20\%).

Table 2: Comfort and heating system parameters for cases with constant water inlet temperature.

\begin{tabular}{|c|c|c|c|c|c|c|}
\hline & $\begin{array}{c}\tau_{\mathrm{c}} \\
{[\%]}\end{array}$ & $\begin{array}{c}\tau_{\mathrm{oh}} \\
{[\%]}\end{array}$ & $\begin{array}{c}\mathrm{t}_{\text {on }} \\
{[\mathrm{min}]}\end{array}$ & $\begin{array}{c}\mathrm{t}_{\text {off }} \\
{[\mathrm{min}]}\end{array}$ & $\begin{array}{c}\mathrm{t}_{\text {on,y }} \\
{[\mathrm{hr}]}\end{array}$ & $\begin{array}{c}\mathrm{E} \\
{[\mathrm{kWh}]}\end{array}$ \\
\hline A & 20.7 & 73.9 & 235 & 780 & 1061 & 1631 \\
\hline B & 69.2 & 27.1 & 27 & 161 & 461 & 1422 \\
\hline C & 62.0 & 18.0 & 22 & 151 & 401 & 1370 \\
\hline
\end{tabular}

Considering the heating system behaviour parameters, important differences between case A and B-C can be noted. The highest values of all the heating system parameters are obtained in case A: the mean heating time $\left(t_{o n}\right)$ in case $\mathrm{A}$ is 235 minutes, that means that emitters are on for around 4 hours for each cycle; the emitters are then re-switched on after 13 hours, as revealed by the mean shutdown time $\left(t_{o f f}\right)$. On the contrary, cases B and C shows a more intermittent behaviour: $t_{o n}$ and $t_{\text {off }}$ are approximately ten times lower than in case A. This different behaviour of the heating system is confirmed by the cumulative distribution of the number of daily on-off cycles of the heating system represented in Figure 5. If the temperature sensor is in A, no more than two on-off cycles are performed, whilst for half of the heating season six daily on-off cycles are performed if the sensor is B or C.

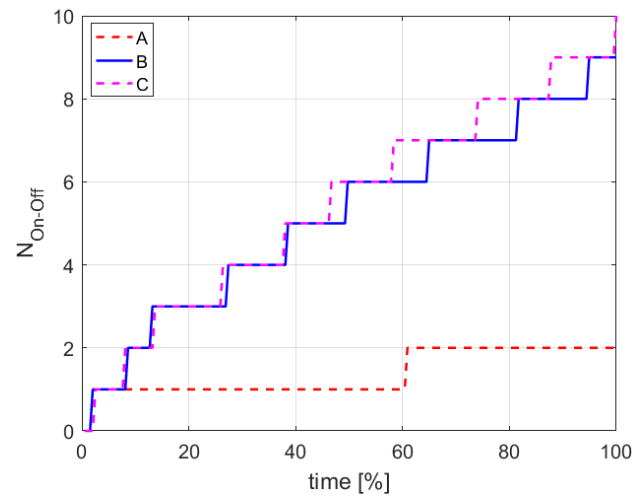

Figure 5: Cumulative distribution of the number of daily on-off cycles.

Moreover, also the seasonal operating time $\left(t_{o n, y}\right)$ is affected by the temperature sensor position: locating the sensor in B or C the heating system is on the $40 \%$ of $t_{o n, y}$ if the sensor is located in A.

Finally, the high overheating and seasonal operating time observed locating the sensor close to the external wall, determine the highest value of the yearly energy demand. When the sensor is in $\mathrm{B}$ and $\mathrm{C}$, the reduction of overheating conditions leads to a lower energy demand ($13 \%$ and $-16 \%$ with respect to case A). These results highlight that it is not recommended to place the indoor sensor close to cold walls (i.e. North external wall) far from the emitter. On the contrary, sensors close to the emitter on the external wall (like in the case of thermostatic valves coupled to radiators) are able to guarantee a sensible reduction of the values of the overheating time.

The reason of the very different results obtained locating the temperature sensor in A could be explained analysing Figure 6, which shows the operative temperature distribution within Office 2 at $1 \mathrm{~m}$ height from the floor when the sensor (identified by the red dot) reaches the upper value of the control band $\left(20.5^{\circ} \mathrm{C}\right)$.

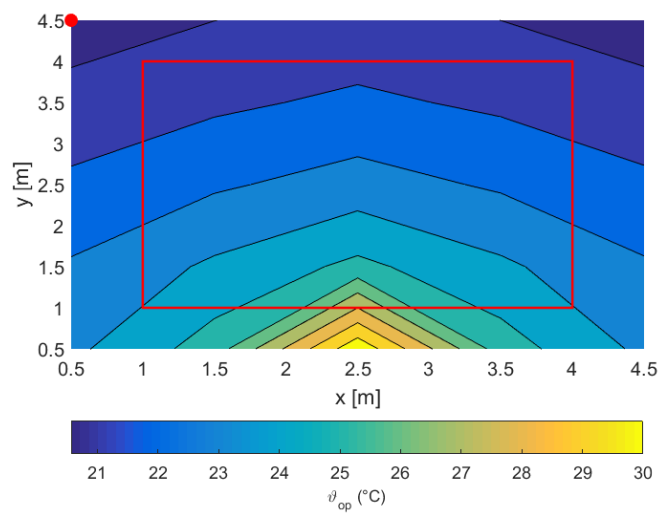

(a)

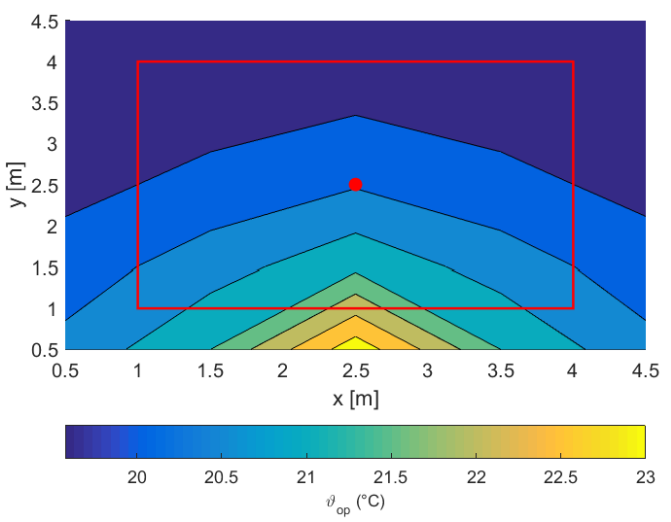

(b)

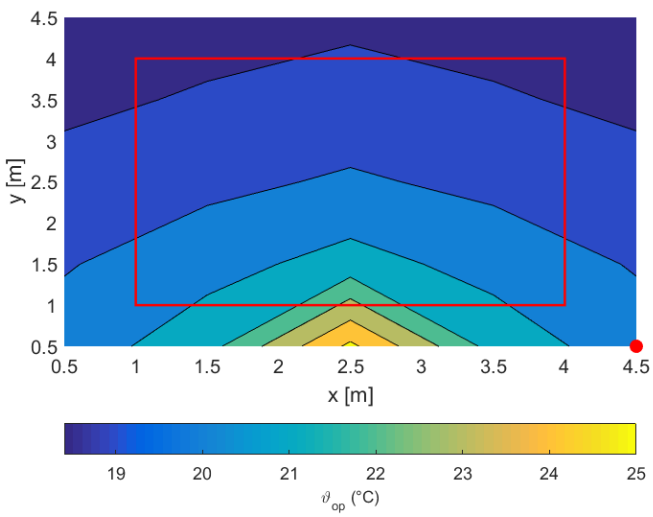

(c)

Figure 6: Operative temperature distribution at $1 \mathrm{~m}$ height from the floor when the sensor reaches $20.5^{\circ} \mathrm{C}$ : (a) sensor in $A$; (b) sensor in $B ;(c)$ sensor in $C$. Red rectangle evidences the comfort zone. 
By comparing the distribution of the operative temperature shown in Figure 6, it can be noted that the operative temperature in correspondence of position $\mathrm{B}$ and $\mathrm{C}$ is very similar to the average temperature of the comfort zone (highlighted by the red rectangle in Figure 6). On the contrary, the operative temperature in position A is always close to the lowest local value of the room. This means that, as it can be seen in Figure 6, when the sensor in position A measures an operative temperature equal to $20.5{ }^{\circ} \mathrm{C}$, the rest of the room is at higher values of the operative temperature; this fact explains the large values of the overheating time observed in the comfort zone in case A.

\section{Cases with weather compensation control}

The adoption of the simplest control strategy, based on a constant radiator inlet water flow at a constant temperature, is responsible of important overheating that have been highlighted for each position of the temperature sensor. In fact, adopting this control strategy radiators always release to the room the same amount of power. On the contrary, heat losses of the offices are variable, depending on the variable external conditions. Therefore, overheating are mainly caused by the extra power provided by radiators, in case of warm external conditions.

For these reasons, in order to improve comfort conditions and to reduce the yearly energy demand, the weather compensation control strategy is usually adopted. By means of this strategy, the radiator inlet water temperature varies according to the weather compensation curve, which relates the inlet water temperature to external conditions, as shown in Figure 7.

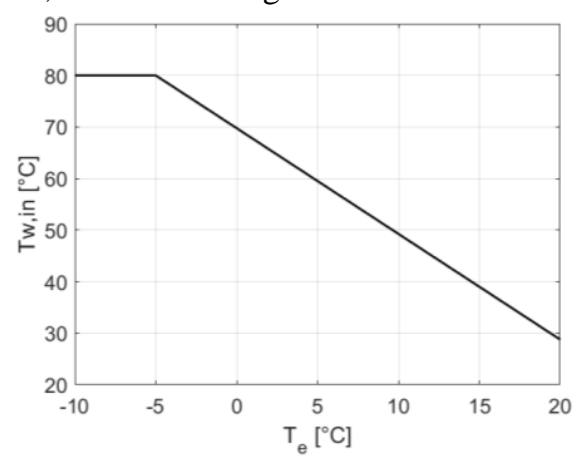

Figure 7: Weather compensation curve $T_{w, \text { in }}$ is the radiator inlet water temperature and $T_{e}$ is the outdoor air temperature.

The cumulative distributions of the mean operative temperature of Office 2, represented in Figure 8, for the different temperature sensor positions show a more similar shape among them, with respect to cases where weather compensation is not adopted (Figure 4). However, if the sensor is located in A, the cumulative distribution mainly lies over the comfort band, revealing again the presence of important overheating. On the contrary, a great reduction of overheating is observed if the sensor is located in $\mathrm{B}$ or $\mathrm{C}$; the cumulative distribution is almost all contained within the target band.

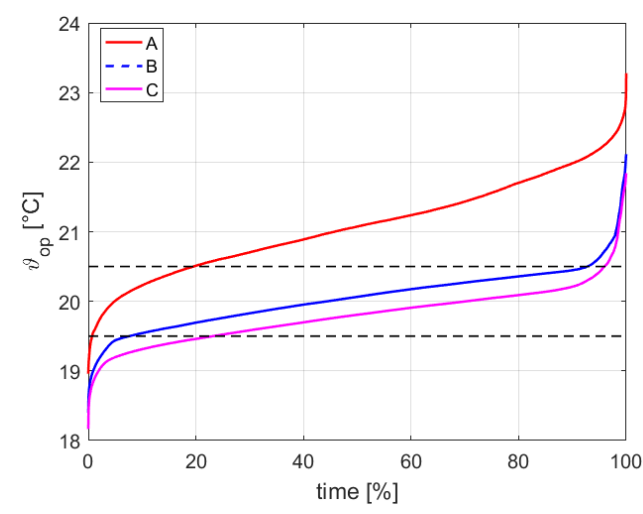

Figure 8: Cumulative distribution of the mean operative temperature of the comfort zone, adopting the weather compensation.

These qualitative assessments are confirmed by the results reported in Table 3: when the temperature sensor is in B or $\mathrm{C}$, the adoption of the weather compensation strongly reduces (about four times) the overheating time $\left(\tau_{\mathrm{oh}}\right)$. On the contrary, if the sensor is placed far from the emitter and near the external wall (case A), the overheating time increases of around $7 \%$. As a consequence, if the sensor is in A the comfort time $\left(\tau_{\mathrm{c}}\right)$ is reduced (lower than $20 \%$ ), whilst in the other cases increments of more than $10 \%$ are observed.

Table 3: Comfort and heating system parameters for cases adopting the weather compensation.

\begin{tabular}{|c|c|c|c|c|c|c|}
\hline & $\begin{array}{c}\tau_{\mathrm{c}} \\
{[\%]}\end{array}$ & $\begin{array}{c}\tau_{\text {oh }} \\
{[\%]}\end{array}$ & $\begin{array}{c}\mathrm{t}_{\text {on }} \\
{[\mathrm{min}]}\end{array}$ & $\begin{array}{c}\mathrm{t}_{\text {off }} \\
{[\mathrm{min}]}\end{array}$ & $\begin{array}{c}\mathrm{t}_{\text {on,y }} \\
{[\mathrm{hr}]}\end{array}$ & $\begin{array}{c}\mathrm{E} \\
{[\mathrm{kWh}]}\end{array}$ \\
\hline $\mathrm{A}$ & 18.8 & 80.5 & 725 & 800 & 2369 & 1635 \\
\hline $\mathrm{B}$ & 85.1 & 7.3 & 132 & 263 & 1456 & 1378 \\
\hline $\mathrm{C}$ & 72.7 & 4.1 & 94 & 215 & 1256 & 1318 \\
\hline
\end{tabular}

The effect due to the sensor position on comfort conditions in presence of weather compensation is due to the heating system behaviour. Significant increase of the mean heating time $\left(t_{o n}\right)$ can be noted for all sensor positions: $+200 \%$ for case $\mathrm{A},+390 \%$ for case $\mathrm{B}$ and $+320 \%$ for case $\mathrm{C}$, whereas the mean shutdown time is increased of $+64 \%$ and $+42 \%$ for cases $\mathrm{B}$ and $\mathrm{C}$ respectively, and only of $2 \%$ for case A.

The increment of $t_{\text {off }}$ is closely related to the increment of $t_{o n}$. In fact, since radiator releases energy for long time, massive building elements (like walls) are able to store more energy, that is released to the room when radiator is turned off, until a thermal equilibrium with the zone is achieved. If the temperature sensor is in A, the mean shutdown time rises of only $2 \%$ because, due to the high response time of the heating system, even without the use of the weather compensation the building massive elements stored a great amount of energy.

If the sensor is in A, the modulation of the power released by radiator leads to a higher time response of the heating system, causing a worsening of the comfort conditions even if the control system is improved. On the contrary, since in position $\mathrm{B}$ and $\mathrm{C}$ the heating system reacts quickly, the use of an improved control system leas to 
better comfort conditions. The weather compensation affects also the number of daily on-off cycles, that becomes less frequent, as can be deduced by the cumulative distribution reported in Figure 9.

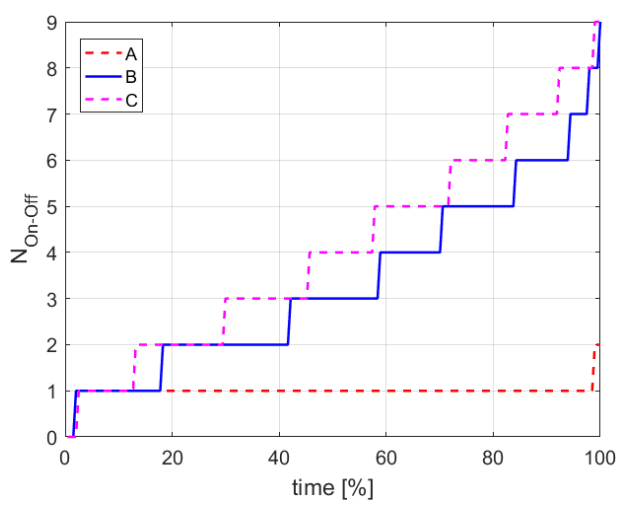

Figure 9: Cumulative distribution of the number of daily on-off cycles, adopting the weather compensation.

Related to the increment of the mean heating time, also the seasonal operating time $\left(t_{o n, y}\right)$ of the heating system strongly increases: increment of $+123 \%,+215 \%$ and $216 \%$ can be observed for cases A, B and C. Finally, the use of the weather compensation and the consequent modulation of the power released by the radiator, leads to a reduction of the energy demand of $3 \%$ and $4 \%$ for cases $\mathrm{B}$ and $\mathrm{C}$ respectively. On the contrary, if the sensor is in $\mathrm{A}$, since the overheating time is increased with respect the case without the adoption of weather compensation, the energy demand has growth of the $0.3 \%$.

In this study the effects of the heating system dynamic response on the generation system (i.e. modulating condensing gas boilers) is not taken into account but it is evident that a longer heating time means lower thermal losses linked to the switch-off periods of the boiler. In addition, the thermal power modulation (activated by the weather compensation) increases the condensation index and the heat recovery linked to the vapor condensation. By considering these aspects the energy saving values becomes more and more significant than the values shown in this study.

As general conclusion, the room temperature sensor must be placed close to the emitters and far from the cold external walls, if possible. In fact, in this case the adoption of the weather compensation leads to higher heating system performance: thermal comfort conditions are improved and energy savings are obtained.

\section{Conclusion}

The spatial distribution of the air temperature in a thermal zone has important implications on both thermal comfort assessment and on the heating system dynamic response. The evaluation of the air temperature distribution by means of simple model that enables a complete analysis of comfort conditions and HVAC system behaviour is a challenging task. In this paper a new simplified zonal model is proposed. The new model enables the evaluation of the spatial distribution of the air temperature, by means of a rough estimation of the air flow, driven only by buoyance forces. The new zonal model, implemented in the ALMABuild library, has been used, as a demonstration of its capabilities, for the evaluation of the effects of the temperature sensor position on comfort conditions and on the heating system behaviour. The analysis is carried out considering three different positions of the temperature sensor (far from the emitter, in the middle of the room and near the emitter), and two different control strategies (constant radiator inlet water flow at nominal water temperature and weather compensation). The results of this study demonstrate that enhanced control strategy does not automatically improves performances of the control system. In fact, it has been proved that indoor comfort condition are influenced by the temperature sensor position in the room. In fact, if the sensor is far from the emitter, best comfort conditions (even if for short time) and lowest energy demand are obtained without weather compensation. On the contrary, if the temperature sensor is in the middle of the room or neat to the emitter, best performances (high comfort and low energy demand) are obtained adopting weather compensation.

Future works are planned for the investigation of the influence of the sensor positioning by varying the emitter typology and configuration, control strategies and modelling in an accurate way the total HVAC system, considering also the hydraulic and the heat generation system, that in this case study have not been considered.

\section{References}

Boukhris Y., Gharbi L., Ghrab-Morcos N. (2009). Modeling coupled heat transfer and air flow in a partitioned building with a zonal model: Application to the winter thermal comfort. Building Simulation, 2.1, 67-74.

Campana J.P., Magni M., Dongellini M, Morini G.L. (2017). The benchmark of a new SIMULINK library for thermal dynamic simulation of buildings. Proceedings from the third Building Simulation Applications conference. Bolzano (Italy), 0810/02/2017.

CEN. (2007). Building components and buildingelements - Thermal resistance and thermal transmittance Calculation method (EN ISO 6946).

Crawley D.B., Pedersen C.O., Lawrie L.K., Winkelmann F.C. (2000). Energy plus: Energy simulation program. ASHRAE Journal 42.4, 49-56.

Daoud A., Galanis N., Bellache O. (2008). Calculation of refrigeration loads by convection, radiation and condensation in ice rinks using a transient 3D zonal model. Applied Thermal Engineering 28.14, 17821790.

EU (2010). Directive 2010/31/UE of the European Parliamentand of the Council of 19 May 2010 on the energy performance of buildings (recast). L. 153/13, Official Journal of European Union. 
Haghighat F., Li Y., Megri A. C. (2001). Development and validation of a zonal model - POMA. Building and Environment 36.9, 1039-1047.

Inard C., Bouia H., Dalicieux P. (1996). Prediction of air temperature distribution in buildings with a zonal model. Energy and Buildings 24.2, 125-132.

Klein S.A., Beckman W.A., Mitchell J.W., Duffie J.A., Duffie N.A., Freeman T.L. (2010) TRNSYS 17: A Transient System Simulation Program. Solar Energy Laboratory, University of Wisconsin, Madison (USA).

Magni M., Campana J.P., Morini G.L. (2017). Dynamic simulations as a tool for the analysis of the interactions among the controllers of HVAC systems. Proceedings from the third Building Simulation Applications conference. Bolzano (Italy), 08-10/02/2017.

Magni M., Campana J.P., Ochs F:, Morini G.L. (2019). Numerical investigation of the influence of heat emitters on the local thermal comfort in a room. Building Simulation. DOI :10.1007/s12273-0.190506-8.

Megri A.C. and Yu Y. (2015). New calibrated zonal model (POMA+) for temperature and airflow predictions. Building and Environment 94.1,109-121.

Musy M., Winkelmann F., Wurtz E., Sergent A. (2002). Automatically generated zonal models for building air flow simulation: principles and applications. Building and Environment 37.8-9, 873-881.
Rajput R.K. (1999). Heat and Mass Transfer.Tata McGrawhill.

Teshome E. J., Haghighat F., (2006). A new generation of zonal models.. ASHRAE Transactions 112.2, 163-174.

Wemhöner C., Hafner B., Schwarzer K. (2000). Simulation of solar thermal systems with CARNOT blockset in the environment Matlab Simulink. Proceedings from Eurosun 2000. Copenhagen (Denmark), June 2000.

Wurtz E., Musy M., Mora L. (1999). Introduction of specific laws in zonal model to describe temperature fields and air flow patterns in mixed ventilated buildings. Journal of the Human-Environment System 3.1, 43-59.

Wurtz E., Deque F., Mora L., Bozonnet E., Trompezinsky S. (2003). SIM_ZONAL: a software to evaluate the risk of discomfort: coupling with an energy engine, comparison with CFD codes and experimental measurements. Proceedings from Eigth International IBPSA2003 Conference. Eindhoven (Netherlands), 11$14 / 08 / 2003$

Wurtz E., Mora L., Inard C. (2006). An equation-based simulation environment to investigate fast building simulation. Building and Environment 41.11, 15711583. 